\title{
Exploring the Pain Experience of Chinese Elderly Patients with Chronic Musculoskeletal Pain and Multimorbidity in Primary Care: A Qualitative Study using a Grounded Theory Approach
}

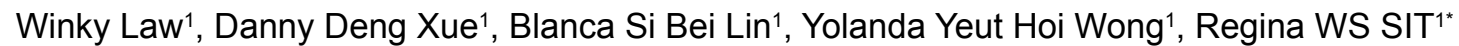

\begin{abstract}
Background: Chronic musculoskeletal pain (CMSP) is a common condition in older people with multimorbidity (MM). Given the complex etiology of CMSP, it is worthwhile to explore the meanings attached to an individual and its interaction with MM. The study aimed to explore the meanings underneath the experience of CMSP and MM, to generate new insight on the support of pain management in the elderly population. Methods: 20 eligible subjects aged between 65 and 80 were recruited through purposive sampling. Semi-structured in-depth interviews were conducted, with data transcript, coded and analyzed using grounded theory approach. Results: Quotes evolved on the interaction between CMSP and MM, with participants expressed worries of pain may affect disease control. Three themes emerged which included the impact of CMSP on the physical and psychosocial well-being among the elderly with MM, the barriers to pain care in the community, and the perception and strategies on pain management. Conclusions: Older people with CMSP and MM were suffering from a significant physical and psychological impact on their well-being. Self-care remains a preferred adjunct in pain management; support should be strengthened at individual (education) and community (urban development) level.
\end{abstract}

Keywords:

chronic pain; grounded theory; multimorbidity; musculoskeletal pain; primary care; qualitative

The Jockey Club School of Public Health and Primary Care, The Chinese University of Hong Kong

Corresponding author

Regina WS SIT: The Jockey Club School of Public Health and Primary Care,

The Chinese University of Hong Kong

Email: reginasit@cuhk.edu.hk

\begin{tabular}{ll} 
& \multicolumn{1}{c}{ Contents } \\
& Introduction \\
$\mathbf{1}$ & Methods \\
1.1 & Study Design \\
1.2 & Participants \\
1.3 & Ethic \\
1.4 & Data Analysis \\
$\mathbf{2}$ & Results \\
2.1 & Theme 1 - Impact of CMSP on Physical, \\
& Psychological and Psychosocial Wellbeing \\
2.3 & Theme 2 - Perceived Barriers for pain management \\
2.3 & Theme 3 - Perception and strategies for chronic pain \\
& management \\
$\mathbf{3}$ & Discussion \\
$\mathbf{4}$ & Conclusion \\
4.1 & Funding Source \\
4.2 & Conflict of Interest \\
4.3 & Authors Contribution \\
$\mathbf{5}$ & References \\
$\mathbf{6}$ & Legend \\
&
\end{tabular}

\section{Introduction}

\section{INTRODUCTION}

Chronic musculoskeletal pain (CMSP) is a common condition in the elderly population, with varying impacts on functional, psychological and social impairment.[1,2] According to the report of the World Health Organization 2015, musculoskeletal health conditions represent a global threat to healthy aging with huge negative effects on the elderly.[3] It is one of the most common reasons for medical consultations, medication use, and hospital admissions, in addition to other healthcare services.[4,5] Multimorbidity (MM), defined as patients living with two or more chronic health conditions, is prevalent in the aging population. It further reduces the quality of life, impairs functional status as well as physical and mental health, and increases mortality.[6] As such, the simultaneous presence of CMSP and MM among older people may have important implications for prognosis and health care utilization.[7]

Pain has long been known to be a multidimensional experience. Although much has been written about exploring individuals' pain experience, they either focused on a single pain disease entity, [8-10]or ignored the importance of in-depth analysis in a qualitative study based on theories and frameworks.[11-13] Furthermore, the existing work did not look into the possible interaction between CMSP and MM, which is common in the elderly population. Given the complex etiology of chronic pain, the meanings attached to an individual and its interaction with $\mathrm{MM}$ is worthwhile to explore. In addition, understanding patients' journey to various pain control methods, the barriers they encountered, and their expectations from health care providers, may provide important information in the formulation of pain management strategies.

This study aimed at exploring the meanings underneath the experience of CMSP and MM, and to generate new insight on the support of pain management in the elderly population. 


\section{Methods}

\subsection{Study Design}

The study was conducted using a grounded theory approach to specifically explore the personal experience of CMSP in the Chinese elderly with MM.[14] Semi-structural interviews were conducted to explore the elderly's pain experience in an in-depth way. Face-to-face interviews were chosen instead of focus groups, given that the Chinese elderly are generally shy to speak up in public. They were allowed to speak in their own words in order to provide the richest possible data and elicit a depth of information with reflective questioning. The theoretical saturation was reached when there was an absence of additional insights and new themes emerged from the participants, which was determined by the consensus between the lead and the third authors of the study.

The interview guide was constructed as a point of reference to solicit participants' pain experience. To obtain an indepth responses, prompts such as "Could you tell me more about that?" or "What do you mean by that?" were used. (Appendix 1) All the interviews were conducted by the lead author who was a postgraduate student in public health. Each participant was interviewed in the consultation room of the primary care clinic, with the length of the interviews lasting from 45 minutes to 1 hour. All interviews were audiotaped and transcribed verbatim. The written transcripts were the primary data source for analysis.

\subsection{Participants}

Theoretical purposive sampling technique was used in the recruitment process in conjunction with data analysis. Purposive sampling is widely used in qualitative research for the identification and selection of information-rich cases who are especially knowledgeable related to the phenomenon of interest.[15] Participants were recruited in a university-affiliated public primary care clinic. The inclusion criteria included participants aged 60 or above; suffered from multiple (two or more) concurrent chronic conditions, defined as "conditions that last a year or more and require ongoing medical attention and/or limit activities of daily living"; [16] and able to communicate in Cantonese or Chinese. The exclusion criteria included the presence of speech or hearing impairments that would hinder the questionnaire interview.

\subsection{Ethic}

The study was approved by the Survey and Behavior Ethics Committee of the Chinese University of Hong Kong. Written informed consent was obtained from all participants.

\subsection{Data Analysis}

We used a multi-stage approach based on grounded theory, which is an inductive data analysis consists of coding data; developing, checking, and integrating theoretical categories; and writing analytic narratives throughout inquiry.[14] The analysis began after the first interview was conducted. The interview conversation was line-byline transcribed in word files, and the transcripts were inputted in Atlas.ti (Version 8.0), a qualitative data analysis software. The transcripts were repeatedly read and coded in two steps, i.e. open coding and axial coding. In the open coding, the keywords and repeated phrases were identified and organized into meaningful and conceptual code. In axial coding, the information with discrete codes was grouped and organized into sub-categories. After that, memoing was done to produce initial themes and define the relationship.

To enhance the credibility and trustworthiness of our analysis, two rounds of coding and discussion were used to develop clear themes. Dependability was enhanced by the accurate independent transcription and comparison of the audio tapes with the transcripts for accuracy. Confirmability was enhanced when the same themes emerged from the data of subsequent group transcripts. The first and third authors independently read transcripts several times to capture a full impression of the data and coded the data independently. Quotations and sections of text were extracted into separate documents under thematic headings and checked for consistency with the narrative content. The authors met to review, compare and contrast their findings and reached agreement on theme categories before the analysis proceeded. The second author acted as an independent arbiter on the emergent analytic account to verify that analysis was systematic and supported by the data. Lastly, the clusters of themes which were relevant to the main theme across the transcripts were identified to produce a final set of themes.

\section{Results}

Twenty subjects were included in the study. The background characteristics of the participants were summarized in table 1. Nine hundred and ninety-five quotations and 160 codes were generated, with 3 themes emerged from our analysis (Figure 1).

Most of the participants believed that CMSK and MM were two independent conditions with no interaction, "I don't think the two conditions are related, they are independent" (quote 16). There were few participants who expressed the pain might worsen disease control, "When I am in pain, the blood pressure goes up" (quote 2); "Bad mood caused by pain makes my glucose and blood pressure difficult to control" (quote 1).

\subsection{Theme 1 - Impact of CMSP on Physical, Psychological and Psychosocial Wellbeing}

The most common complaint was the debilitating physical effects of pain on their daily living. Majority of the participants indicated that CMSP interrupted them from doing exercises, which is essential in chronic disease management. CMSP also hindered them from participating in outdoor activities, including going to other housing estates or districts, and taking a trip, because they were 'unable to walk for a long distance', 'too exhausted', 'no 
Table 1 - The General Characteristics of Each Study Participant

\begin{tabular}{|c|c|c|c|c|c|c|}
\hline $\begin{array}{c}\text { Subject } \\
\text { Code }\end{array}$ & Gender & Age & Illnesses/Diseases & $\begin{array}{c}\text { Educational } \\
\text { Level }\end{array}$ & Housing & Living Status \\
\hline 1 & $\mathrm{M}$ & 75 & Diabetes, High Cholesterol, Hypertension & S2 & PRH & With 2 people \\
\hline 2 & $\mathrm{~F}$ & 70 & Hypertension, High Cholesterol, High Blood Sugar & P6 & PRH & With 1 people \\
\hline 3 & $\mathrm{~F}$ & 65 & $\begin{array}{l}\text { Diabetes (Hyperglycaemia), Hypertension, High } \\
\text { Cholesterol, Mental Disorder }\end{array}$ & P6 & PRH & With 1 people \\
\hline 4 & F & 70 & $\begin{array}{l}\text { Mental Disorder (Anxiety and Depression), } \\
\text { Hypertension, Heart Disease }\end{array}$ & P6 & $\mathrm{PH}$ & With 2 people \\
\hline 5 & M & 76 & $\begin{array}{l}\text { Hypertension, Diabetes, Esophageal Ulcer, } \\
\text { Bronchiectasia, Cataract }\end{array}$ & P6 & PRH & With 1 people \\
\hline 6 & F & 67 & $\begin{array}{l}\text { Pelvic Surgery (Fall Injury), Gastroesophageal } \\
\text { Reflux Disease, Irritable Bowel Syndrome, } \\
\text { Insomnia }\end{array}$ & S3 & PRH & Single living \\
\hline 7 & $\mathrm{~F}$ & 71 & Mental Disorders (Depression), Nasal Hydatoncus & P3 & PRH & Single living \\
\hline 8 & $\mathrm{~F}$ & 68 & Mild Glaucoma, cardiac arrthymia & P6 & HOSF & With 1 people \\
\hline 9 & M & 72 & $\begin{array}{l}\text { Heart Disease (With Surgery), Gout, Hypertension, } \\
\text { High Cholesterol }\end{array}$ & S6 & HOSF & With 2 people \\
\hline 10 & F & 68 & $\begin{array}{l}\text { Hyperuricemia, Hypertension, Heart Disease, } \\
\text { Mental Disorder }\end{array}$ & P6 & HOSF & With 3 people \\
\hline 11 & $\mathrm{~F}$ & 74 & Hypertension, High Cholesterol & P1 & HOSF & Single living \\
\hline 12 & $\mathrm{~F}$ & 70 & Hypertension, Fatty Liver & S6 & PH & With 3 people \\
\hline 13 & $\mathrm{~F}$ & 75 & $\begin{array}{l}\text { Hypertension, Cataract, Mild Stroke, Kidney Stone, } \\
\text { Gallstone, Hapatitis B Carrier, Hyperglycemia }\end{array}$ & P6 & PRH & With 3 people \\
\hline 14 & $\mathrm{~F}$ & 80 & $\begin{array}{l}\text { Chronic Cough, Hypertension, Osteoporosis, Pelvic } \\
\text { Fracture Surgery }\end{array}$ & P6 & HOSF & Single living \\
\hline 15 & F & 69 & $\begin{array}{l}\text { Hypertension, Cardiac Dysrhythmia, Eczema, Bone } \\
\text { Tuberculosis (Spine, Kyphosis) }\end{array}$ & P6 & PRH & With 1 people \\
\hline 16 & $\mathrm{~F}$ & 69 & Hypertension, High Cholesterol & P6 & PRH & With 2 people \\
\hline 17 & F & 69 & $\begin{array}{l}\text { Hypertension, Sleep Apnea, Insomnia, } \\
\text { Osteoporosis, Nasal Allergy }\end{array}$ & S5 & HOSF & With 1 people \\
\hline 18 & M & 74 & $\begin{array}{l}\text { Hypertension, Heart Disease (With Surgery), } \\
\text { Tuberculosis of Lung, High Cholesterol }\end{array}$ & S2 & PRH & With 1 people \\
\hline 19 & $\mathrm{~F}$ & 71 & $\begin{array}{l}\text { Allergic Airway (Cough, }>5 \text { years), Insomnia } \\
\text { (Mild Post-Traumatic Stress Disorder, }>10 \text { Years) }\end{array}$ & P3 & HOSF & With 1 people \\
\hline 20 & $\mathrm{~F}$ & 71 & Mild Stroke, Deafness (Right Ear), Hypertension & P3 & PRH & With 2 people \\
\hline
\end{tabular}

Abbreviation: female (F), Home Ownership Scheme Flat (HOSF), male (M), primary (P), Private Hosing (PH), Public Rental Housing (PRH), secondary (S)

sense of security', 'feeling unmotivated', and 'not in the mood' [quote 6, 7]. Moreover, pain also affected their social roles, especially among women who were responsible for household chores, such as 'I can't carry heavy objects when performing my housework' [quote 6, 7]. Besides, pain also impacted older people in the psychological aspect. The most commonly expressed feeling was 'uncomfortable', followed by 'labile mood', 'exhausting', 'disturbing' and 'discouraging'. The bothersome of CMSP was also expressed as "Pain affecting all part of lives ... constant pain all over, bothering you days and nights, very uncomfortable and just can 't get rid of it', [quote 11].

2.2 Theme 2 - Perceived Barriers for pain management Participants were frustrated and expressed helplessness in seeking medical care, "I don't know where or how to ask for help' [quote 12, 13]". Some participants had given up seeking help from others because they believe "seeking help could not relieve their symptoms and it was useless to tell others" [quote 14]. They also had great concern on the possible side effects of the analgesic medications on their pre-existing illnesses, and they had the impression that the only way doctors could help was to prescribe pain-killers,
"I have stopped visiting doctors and taking oral drug. I think taking too many medicines is bad and have side effect" [quote 16]. Some of the participants mentioned that they were only offered the option of surgery in their pain management. They were also dissatisfied with the relatively short medical consultation time and the long referral queue to physiotherapy. Participants were keen to visit traditional Chinese Medicine practitioners, though they expressed the associated financial burden. In general, participants found exercise was a good way to relieve pain and to improve their disease control. However, they mentioned several factors that hindered them from doing exercise, which included 'extremely bad pain', 'have lots offamily responsibility', 'no time', 'absence of equipment', ' a lot of facilities users in the park', 'always feeling tired', and 'forgot some movements that learned from exercise class" [quote 17, 22, 23, 24].

\subsection{Theme 3 - Perception and strategies for chronic} pain management

Participants described a wide range of strategies to cope with their CMSP. They were fully aware of the importance of self-care and preferred to use their self-administered 
methods in pain management, "I am on my own to find ways in managing pain conditions" [quote 12], "I'd rather work out on my own if you just offer painkiller tablets. I have to help myself" [quote 18]. Participants were keen to use complementary care, such as topical oil, cream or patch in combination with self-massage. Although they understand that the measures could only provide short-term pain relief, "At least I don't have to take anything orally when I apply the rub, taking oral drugs are bad for the liver and kidneys", [quote 15]. For those who preferred to do exercise, they generally did not intend to relieve pain, but to maintain the normal functioning of body, to have social activity, to relax the muscle and to keep them physically active, "If you sit all day and not moving, muscles will become tense; during the exercise, we can chat with others, and it helps to relax" [quote 29].

\section{Discussion}

In spite of the international argument by pain specialists for the recognition of chronic pain as a disease in its own right,[17] patients tend not to interpret pain as a disease, nor do they associate pain with their pre-existing chronic conditions. Consistent with existing literature, pain is generally regarded as a factor leading to poor control of chronic diseases. $[18,19]$ The meaning of pain attached to patients with MM remains to be its negative influence on their physical and psychosocial health, [20] which is often perceived as helplessness, hopelessness, and loss of control in everyday life.[21] Similar to Western literature, the barriers in pain management included limited access to pain management services, worries about the side effects of pain killers, cost of therapeutic agents and the lack of time and information from their healthcare providers.[8, 12] Frustrations about pain not "being heard" or "understood" contributes to the distrust and dissatisfaction in the medical process.[11] [22]

Self-care is often the first choice for people with CMSP, which includes the use of non-prescription medications without doctor's supervision, as well as the use of other modern and traditional treatment methods with no consultation of healthcare providers. The holistic view on health, ability to take control over one's own health, preference of natural treatment methods, as well as the concern about potential side effects of pharmaceutical products, all contribute to the increased use of self-care. Some self-care interventions are effective adjuncts to the usual care for reducing chronic pain and related disability. [23] Our participants preferred to use exercise as their own self-care measure, among which Tai Chi and stretching exercise were most popular and perceived to be useful. Unfortunately, the very crowded living environment have restricted them from doing too much exercise. In highly dese cities, older people often spend a considerable amount of time in public parks. It is commonly recognized that the social dimension of environments have a significant influence on the health and well-being of the elderly. With the local aging population, social and public policy on urban planning should be more responsive to the aspirations and needs of our older people.[24] A clear understanding of key planning and design for public open space and the installation of suitable outdoor fitness facilities would be important to enhance the self-management elderly in pain and chronic disease management.

There may be potential risks with self-care; the nonawareness of using various products in combination with prescribed medications may lead to adverse drug interactions, and the partial response to self-care measures may mask more serious diseases, with the consequent prolongation of diagnosis.[25] Therefore, to take the responsibility of their own health and participate actively in the treatment process, older people should possess certain knowledge and skills, and they should be well-informed about the appropriate self-care methods and critical conditions that warrant formal medical consultation.[26] Care and support planning comprises a collaborative, personalized care planning conversation between older people and healthcare providers should be encouraged. The conversation should bring together information gathered by the healthcare professional and the goals, values and priorities of the elderly with CMSP and MM, allowing time to develop and record a care and support plan.[27]

Limitations existed in this study. The enrolled subjects were mostly female coming from a lower socio-economic status, their overall experience may not reflect the majority of older people with CMSP and MM. In addition, only one interview was conducted for each participant; multiple interviews may potentially enhance a greater level of trust and perhaps more themes can be generated.

\section{Conclusion}

CSMP was generally not considered as a form of chronic disease in patients' perspective; however, pain intensity was perceived as a factor that would affect disease control. Apart from dealing with the physical and biopsychosocial challenges, older people with MM were further deprived of effective treatment options, attributed to factors including the potential side effects of medications on their premorbid medical conditions, and the painful joints that reduced their exercise participation. Self-care remains a priority adjunct to clinical treatment in older people. Proper channels should be established to inform the elderly on appropriate self-care methods and circumstances to seeking medical care. Urban development should equip facilities that enable the use of self-care measures, especially space and facilities for exercise.

\subsection{Funding Source}

No funding received for this study.

\subsection{Conflict of Interest}

None

\subsection{Authors Contribution:}

WL and RWSS participated in the conception and design 
of the study. WL conducted the semi-structural interviews and transcript the data. WL and BCBL coded and analyzed the data separately. WL, DXD and RWSS interpreted the results. WL, DXD and YYHW drafted the manuscript, and RWSS critically revised the manuscript for important intellectual content and approved the final version of the manuscript. The corresponding author attested that all listed authors meet authorship criteria and that no others meeting the criteria have been omitted.

\section{Abbreviations: \\ CMSP: Chronic Musculoskeletal Pain MM: Multimorbidity}

\section{References}

1. Kroenke K, Outcalt S, Krebs E, Bair MJ, Wu J, Chumbler N, Yu Z. Association between anxiety, health-related quality of life and functional impairment in primary care patients with chronic pain. General hospital psychiatry. 2013;35(4):359-65.

2. de Heer EW, Gerrits MM, Beekman AT, Dekker J, van Marwijk HW, de Waal MW, Spinhoven P, Penninx BW, van der Feltz-Cornelis CM. The association of depression and anxiety with pain: a study from NESDA. PloS one. 2014;9(10):e106907.

3. Briggs AM, Cross MJ, Hoy DG, Sanchez-Riera L, Blyth FM, Woolf AD, March L. Musculoskeletal health conditions represent a global threat to healthy aging: a report for the 2015 World Health Organization world report on ageing and health. The Gerontologist. 2016;56(supp1_2):S243-55.

4. Blyth FM, Briggs AM, Schneider CH, Hoy DG, March LM. The Global Burden of Musculoskeletal Pain-Where to From Here? American journal of public health. 2019;109(1):35-40

5. Zaki LR, Hairi NN. Chronic pain and pattern of health care utilization among Malaysian elderly population: National Health and Morbidity Survey III (NHMS III, 2006). Maturitas. 2014;79(4):435-41.

6. Barnett K, Mercer SW, Norbury M, Watt G, Wyke S, Guthrie B. Epidemiology of multimorbidity and implications for health care, research, and medical education: a cross-sectional study. The Lancet. 2012;380(9836):37-43

7. Scherer M, Hansen H, Gensichen J, Mergenthal K, Riedel-Heller S, Weyerer S, Maier W, Fuchs A, Bickel H, Schön G, Wiese B. Association between multimorbidity patterns and chronic pain in elderly primary care patients: a cross-sectional observational study. BMC family practice. 2016;17(1):68.

8. Slade SC, Molloy E, Keating JL. Listen to me, tell me': a qualitative study of partnership in care for people with non-specific chronic low back pain. Clinical Rehabilitation. 2009;23(3):270-80.

9. Crowe M, Whitehead L, Jo Gagan M, Baxter D, Panckhurst A. Selfmanagement and chronic low back pain: a qualitative study. Journal of advanced nursing. 2010;66(7):1478-86.

10. Snelgrove S, Liossi C. Living with chronic low back pain: a metasynthesis of qualitative research. Chronic illness. 2013;9(4):283301.

11. Teh CF, Karp JF, Kleinman A, Reynolds III CF, Weiner DK, Cleary PD. Older people's experiences of patient-centered treatment for chronic pain: a qualitative study. Pain Medicine. 2009;10(3):521-30.

12. Lansbury G. Chronic pain management: a qualitative study of elderly people's preferred coping strategies and barriers to management. Disability and rehabilitation. 2000;22(1-2):2-14

13. Upshur CC, Bacigalupe G, Luckmann R. "They don't want anything to do with you": Patient views of primary care management of chronic pain. Pain Medicine. 2010;11(12):1791-8

14. Corbin J, Strauss AL, Strauss A. Basics of qualitative research. Sage; 2015.

15. Palinkas LA, Horwitz SM, Green CA, Wisdom JP, Duan N, Hoagwood $\mathrm{K}$. Purposeful sampling for qualitative data collection and analysis in mixed method implementation research. Administration and policy in mental health and mental health services research. 2015;42(5):53344.

16. Parekh AK, Barton MB. The challenge of multiple comorbidity for the US health care system. Jama. 2010;303(13):1303-4.

17. Raffaeli W, Arnaudo E. Pain as a disease: an overview. Journal of pain research. 2017;10:2003.

18. Krein SL, Heisler M, Piette JD, Makki F, Kerr EA. The effect of chronic pain on diabetes patients' self-management. Diabetes care. 2005;28(1):65-70

19. Krein SL, Hofer TP, Holleman R, Piette JD, Klamerus ML, Kerr EA. More than a pain in the neck: how discussing chronic pain affects hypertension medication intensification. Journal of general internal medicine. 2009;24(8):911-6.

20. Loeser JD, Melzack R. Pain: an overview. The lancet. 1999;353(9164):1607-9.

21. Andersen LN, Kohberg M, Herborg LG, Søgaard K, Roessler KK. "Here we're all in the same boat"-a qualitative study of group based rehabilitation for sick-listed citizens with chronic pain. Scandinavian journal of psychology. 2014;55(4):333-42.

22. Walker J, Holloway I, Sofaer B. In the system: the lived experience of chronic back pain from the perspectives of those seeking help from pain clinics. Pain. 1999;80(3):621-8.

23. Du S, Yuan C, Xiao X, Chu J, Qiu Y, Qian H. Self-management programs for chronic musculoskeletal pain conditions: a systematic review and meta-analysis. Patient education and counseling. 2011;85(3):e299-310.

24. Buffel T, Phillipson C, Scharf T. Ageing in urban environments: Developing 'age-friendly'cities. Critical Social Policy. 2012;32(4):597-617.

25. Kovačević I, Kogler VM, Turković TM, Dunkić LF, Ivanec Ž, Petek D. Self-care of chronic musculoskeletal pain-experiences and attitudes of patients and health care providers. BMC musculoskeletal disorders. 2018;19(1):76.

26. Newman S, Steed L, Mulligan K. Self-management interventions for chronic illness. The Lancet. 2004;364(9444):1523-37.

27. Duffield SJ, Ellis BM, Goodson N, Walker-Bone K, Conaghan PG, Margham T, Loftis T. The contribution of musculoskeletal disorders in multimorbidity: implications for practice and policy. Best Practice \& Research Clinical Rheumatology. 2017;31(2):129-44. 


\section{Legend}

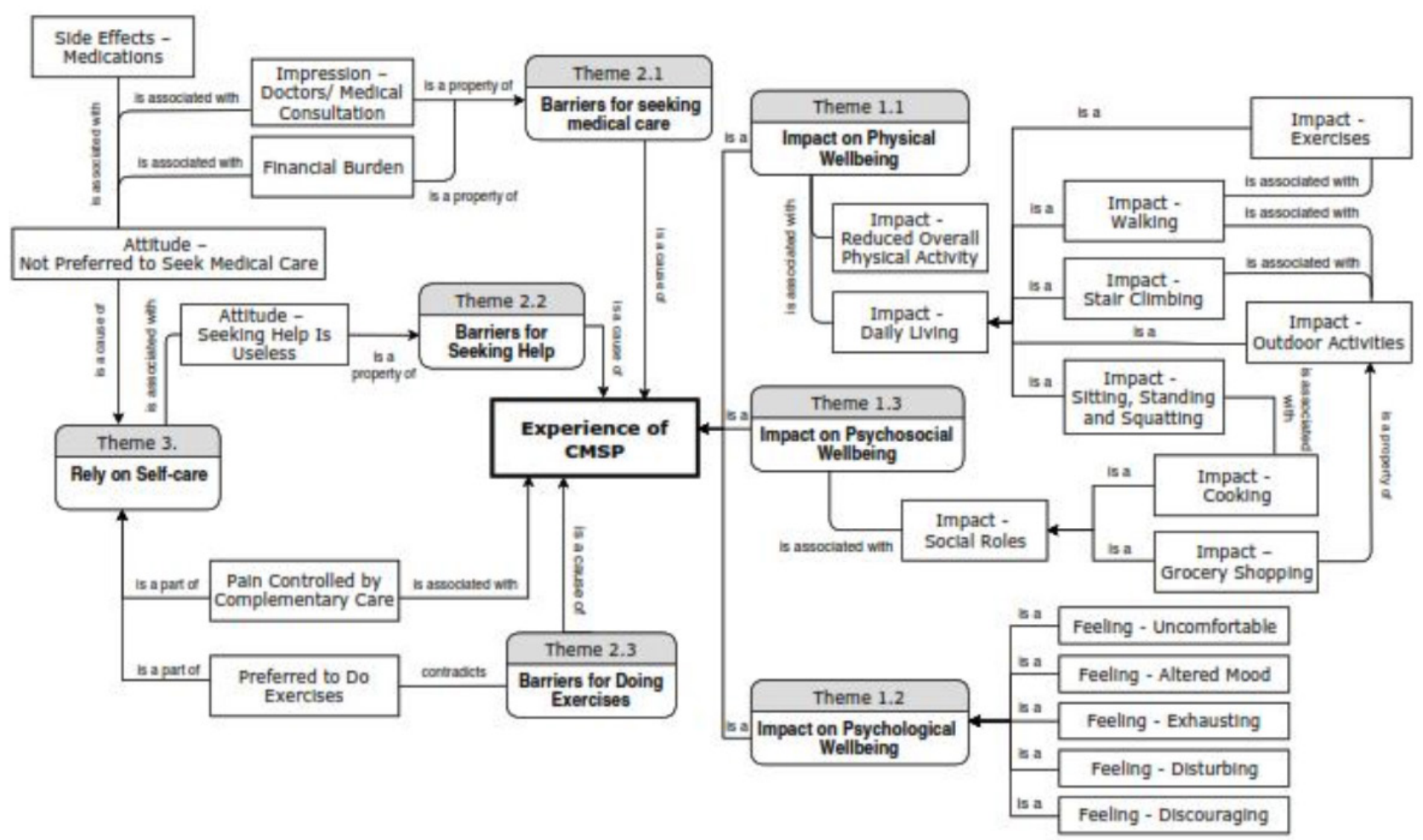

Figure 1 - Coding process of qualitative data analysis through a grounded theory data analysis techniques

\section{Appendix 1: Interview Guide:}

1. Can you tell us about your pain?

2. How would you describe your pain?

3. How do you feel as a patient with chronic musculoskeletal pain and multiple medical conditions?

4. How does the pain affect your daily life?

5. As a patient with multiple medical conditions, how do you cope with your pain?

6. Do you find any pain control methods that are useful or not useful?

7. As a patient with chronic medical illnesses, what are the challenges you have in pain management?

8. Let's say this discussion was going to share with your doctors with the goal to help better treat your pain, what would you like to tell them? 